\title{
Spanish science policy Socialists name science team
}

\section{Oncogenes cause cancer institute to change tack}

\section{Washington}

Now that some specific human genes have been implicated in the causation of cancer, what should happen to more traditional areas of cancer research? That question is being asked by policymakers at the National Cancer Institute (NCI) faced with the task of distributing $\$ 983$ million a year on cancer research.

Since the discovery that a difference of just one nucleotide can distinguish a human cancer gene from its normal counterpart (see Nature 11 November 1982 , p.103), interest in the study of oncogenes has increased dramatically. Some researchers in the field are hoping for a corresponding increase in NCI's involvement with molecular and cellular genetics. But NCI's policy at the moment is, in the words of its director, Vincent DeVita Jr, "to let the system drive itself". That is, he wants researchers at the "cutting edge" of the field, and those in affected areas, to initiate proposals and have the system review them, so the work will expand only as the peer review system allows.

Grant applications in NCI's $\$ 100$ million competing grants programme are scored by their peer reviewers. DeVita says that proposals relating to oncogenes and sequencing have been getting the highest scores lately, so the work seems to be expanding naturally. DeVita says his policy choice is not whether to expand the attention given to oncogenes, but whether artificially to set limits on it, and this he declines to do.

One exception to NCI's laissez faire policy, however, is the attempt to make the Frederick cancer research facility in Frederick, Maryland into a major centre of activity of the "cutting edge". DeVita is looking for a new principal investigator to run Frederick's basic research programme, and is hoping to get someone of international stature in the field of oncogenes.

The new principal investigator at Frederick will manage not only the $\$ 8$ million basic research programme there, but also an additional $\$ 2$ million to be reprogrammed from other work.

DeVita has already enhanced Frederick's role in key areas of molecular genetics. Two years ago he invited some of the groups at NCI to move from Bethesda out to Frederick, which they did. And a year ago DeVita appointed Peter Fischinger, who worked with George Todaro in NCI's viral carcinogenesis laboratory, to be associate director of NCI. Frederick is one of his responsibilities.
Another is keeping track of the emerging oncogene story and its implications for other programmes. "In a sense we anticipated these breakthroughs", Fischinger says, noting that approximately $\$ 40$ million was spent on this work in 1982 and $\$ 43$ million is to be spent in 1983 .

But if NCI allows spending on oncogene research to expand naturally, does this mean less prominence for important traditional fields such as chemotherapy? DeVita says that some other work must obviously go, given the fact that NCI is unlikely to receive any budget increases in the next few years. He notes that chemotherapy has been cut by about 30 per cent in the past six years on scientific grounds: "some things we didn't need to do any more", he says. And, as explained by Alan Rabson, director of NCl's division of cancer biology and diagnosis, "if you understand oncogenes you may learn where to go in chemotherapy. It may open up whole new areas of chemotherapy".

But NCI's experience in another area of cancer research may be making DeVita wary of establishing a new programme or making other institutional changes. In 1964, NCI established what came to be called the Special Virus Cancer Program a targeted research effort based on the belief that the discovery of a human cancer virus was just around the corner. In time, the programme got a bad name - it attracted money and policy attention but real scientific progress did not keep pace.

In due course NCI's Cancer Advisory Board appointed a group to review the Special Virus Cancer Program. Headed by Norton Zinder of Rockefeller University, it concluded that the programme had indeed gone too far. It has since been broken up and integrated into other work at $\mathrm{NCl}$. Some of the work, however, contributed to the recent outbreak of research on human oncogenes since most, if not all, of them are closely related to viral oncogenes. What is more there is at last firm evidence of a human cancer caused by a retrovirus.

Today, Zinder comments on these newer, more profound breakthroughs. "In three years I can see there might be a need for a special program, but they're still exploring the basic implications." Using an analogy from American baseball, he said, "we're still running to first base with a good throw coming in from third". Clearly, NCI's system has more steps to take before anyone will feel confident that they can hit a home run and recommend a special, targeted programme.

Deborah Shapley

\section{Barcelona}

IN Spain, the new socialist government is likely to spend more on science and technology than its predecessor, at least if its election promises are carried out. Since the elections on 28 October, the Spanish socialist party (PSOE) has an absolute majority in both houses of parliament for the next four years. Its leader, Felipe González, is the first socialist prime minister in Spain in peacetime.

In the slogans used by PSOE during the election campaign, the main proposal was a "change" but a moderate change. That was evident in the science and technology programme, which was uncontroversial enough to have been supported by any of the major parties contending the elections.

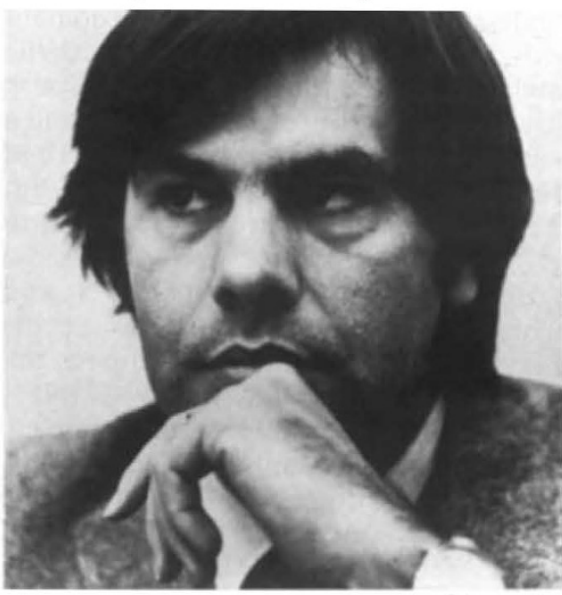

Felipe González, committed to doubling the share of the GNP to go to scientific research

An increase in the present level of spending in research and development is proposed in the socialist programme. An increase in public research funding should raise spending on research and development as a proportion of the gross national product (GNP) from its present 0.4 per cent to 0.8 per cent in the next four years, an average annual increase of 22 per cent. Besides these financial measures, the programme contains a number of more general proposals, including the definition of priorities, reform of the administrative structure of research centres and a reform of the situation of research staff.

The new Minister of Education and Science, Jose María Maravall, is a sociologist. From now on, there will be two people with direct responsibility for universities and research: Dr Carmina Virgili, a professor of geology, has been appointed Secretary of State for Universities while Dr Emilio Munoz, a membrane biochemist, is the new Director General of Science Policy. A detailed programme for the next four years has been announced.

Pedro Puigdoménech 